\title{
CONFLITOS DO USO DA TERRA EM ÁREAS PROTEGIDAS POR LEI NO PARQUE ESTADUAL DO RIO PRETO E ZONA DE AMORTECIMENTO, MINAS GERAIS
}

\section{LAND-USE CONFLICTS IN AREAS PROTECTED BY LAW IN THE RIO PRETO STATE PARK AND BUFFER ZONE, MINAS GERAIS}

\author{
Marcelo Angelo Ferreira \\ Mestre em Ciência Florestal, UFVJM, Brasil \\ marcelo.ferreira@ufvjm.edu.br
}

\section{Luciano Cavalcante de Jesus França \\ Doutorando em Engenharia Florestal, UFLA; Prof. substituto do IFMG, Brasil lucianocjfranca@gmail.com}

\begin{abstract}
Marcelino Santos de Morais
Doutor em Geografia, UFMG; Prof. adjunto da Faculdade Interdisciplinar em Humanidades, UFVJM, Brasil marcelino.morais@ufvjm.edu.br
\end{abstract}

\section{Bernardo Machado Gontijo}

Doutor em Desenvolvimento Sustentável, UnB; Prof. associado do Instituto de Geociências; UFMG, Brasil bmgontijo@yahoo.com.br

\section{Eric Bastos Gorgens}

Doutor em Recursos Florestais, ESALQ - USP; Prof. adjunto da Faculdade de Ciências Agrárias, UFVJM, Brasil

eric.gorgens@ufvim.edu.br

\section{Danielle Piuzana Mucida}

Doutora em Geologia, UnB; Profa. associada da Faculdade Interdisciplinar em Humanidades, UFVJM, Brasil danielle.piuzana@ufvim.edu.br

\section{Resumo}

O presente estudo objetivou identificar áreas de conflitos em Áreas de Proteção Permanente (APP) e Áreas de Uso Restrito (AUR) no Parque Estadual do Rio Preto (PERP) e sua Zona de Amortecimento (ZA). O trabalho parte das evidências de entender o estado de conservação no PERP e sua ZA aplicando as diretrizes de APP e AUR apresentados no Código Florestal Brasileiro vigente. Empregando recursos disponíveis em ambiente SIG (sistema de informações geográficas), delimitou-se e mapeou-se classes de uso da terra e as APP de nascentes e cursos d'água; bordas de tabuleiros ou chapadas; áreas com declividade superior a $45^{\circ}$; áreas com altitude superior a $1800 \mathrm{~m}$; e AUR com base nos parâmetros, definições e limites estabelecidos pela Lei $n^{\circ} 12.651$. A partir da sobreposição destes mapas analisou-se a ocorrência de conflito de uso na área. As classes de uso da terra foram: Afloramento Rochoso (49,70\%), Formação Campestre (28,34\%), Agropecuária $(2,70 \%)$, Solo Exposto $(4,62 \%)$ e Água $(0,29 \%)$ Dentre as categorias de APP observamos maior ocorrência das APP nascentes $(8,41 \%)$ e cursos d'água $(54,24 \%)$. As APP 
declividade $>45^{\circ}(0,58 \%)$ e altitude superior a $1800 \mathrm{~m}(0,03 \%)$ apresentaram menor ocorrência. Os usos da terra em APP do tipo nascente e cursos d'água e AUR foram mais expressivos nas classes de Afloramento Rochoso, Formação Florestal e Formação Campestre. As classes de Agropecuária e Solo Exposto apresentaram baixa incidência no conflito de uso em todas as APP e AUR analisadas. Porém, ao analisar sua ocorrência entre as categorias de APP verificou-se maior ocorrência de uso indevido nas APP nascentes e cursos d'água. Com base nos resultados observamos a eficiência do uso das ferramentas nos SIG, confirmando a potencialidade deste como subsídio nas políticas públicas e gestão eficiente do uso da terra.

Palavras-chave: Área de Uso Restrito, Código Florestal, Ordenamento Territorial, SIG, Unidades de Conservação.

\section{Abstract}

This study aimed to identify conflict areas in Permanent Protection Areas (APP) and Restricted Use Areas (AUR) in the Rio Preto State Park (PERP) and its Buffer Zone (ZA). The work starts from the evidence of understanding the conservation status in the PERP and its ZA applying the APP and AUR guidelines presented in the current Brazilian Forest Code. Using resources available in a GIS (geographic information system) environment, land use classes and APPs of springs and watercourses were delimited and mapped; board or plate edges; areas with a slope greater than $45^{\circ}$; areas with altitude above $1800 \mathrm{~m}$; and AUR based on the parameters, definitions and limits established by Law No. 12,651. From the superposition of these maps, the occurrence of use conflicts in the area was analyzed. The land use classes were: Rocky Outcrop (49.70\%), Campestre Formation (28.34\%), Agriculture (2.70\%), Exposed Soil (4.62\%) and Water (0.29\%). Among the APP categories, we observed a higher nascent APP (8.41\%) and watercourses (54.24\%). The APP slope > $45^{\circ}(0.58 \%)$ and altitude above $1800 \mathrm{~m}(0.03 \%)$ had less occurrence. The land uses in spring-type APP, watercourses, and AUR were more expressive in the Rocky Outcrop, Forest Formation, and Campestre Formation classes. The Agricultural and Exposed Soil classes showed a low incidence of conflict of use in all analyzed APP and AUR. However, when analyzing its occurrence among the APP categories, there was a higher occurrence of misuse in springs and watercourses APP. Based on the results, we observed the efficiency of the use of tools in GIS, confirming its potential as a subsidy in public policies and efficient management of land use.

Keywords: Restricted Use Area, Forest Code, Spatial Planning, GIS, Conservation Units.

\section{INTRODUÇÃO}

A conservação ambiental, um dos grandes desafios da humanidade, consiste na concentração de esforços e recursos para a conservação e recuperação de áreas naturais consideradas estratégicas, das quais vários ecossistemas são dependentes. A conservação da biodiversidade é melhor sucedida minimizando as ações humanas em 
paisagens intactas e não fragmentadas (BARLOW et al., 2016; BETTS et al., 2017), como áreas protegidas por Unidades de Conservação (MORANDI et al., 2020).

No Brasil, a criação do Sistema Nacional de Unidades de Conservação (SNUC), pela Lei Federal n ${ }^{\circ}$ 9.985/2000, dividiu em duas categorias as Unidades de Conservação (UC) em Proteção Integral e Uso Sustentável (BRASIL, 2000). A conservação das UC de Proteção Integral relaciona-se diretamente às atividades existentes em seu entorno definidas como Zona de Amortecimento (ZA), onde as atividades antrópicas estariam restritas e sujeitas a normas específicas para minimizar os impactos negativos sobre as UC (BRASIL, 2000). Já a Resolução CONAMA n 428 de 2010 (BRASIL, 2010) trata do licenciamento de empreendimentos que possam afetar a UC ou sua ZA, com o objetivo de não permitir o uso e ocupação do solo de forma indevida.

Tendo em vista que UC são áreas protegidas, a Lei $n^{\circ} 12.651$, de 25 de maio de 2012, conhecida como "Novo Código Florestal", auxilia na gestão do uso da terra de seu entorno. Esta lei consiste em instrumento que estabelece as normas gerais sobre a proteção da vegetação, Áreas de Preservação Permanente (APP), áreas de Reserva Legal (ARL) e Áreas de Uso Restrito (AUR). APP possuem a função de preservar recursos hídricos, paisagem, estabilidade geológica e biodiversidade, facilitando o fluxo gênico de fauna e flora, protegendo o solo e assegurando o bem-estar das populações humanas (FEISTAUER et al., 2017). Já as AUR permitem o manejo florestal sustentável e o exercício de atividades agrossilvipastoris, bem como, a manutenção da infraestrutura física associada ao desenvolvimento das atividades, observando boas práticas agronômicas, sendo vedada a conversão de novas áreas, excetuadas as hipóteses de utilidade pública e interesse social (BRASIL, 2012; SOARES-FILHO et al., 2014; FRANÇA et al., 2018b; FRANÇA et al., 2020).

O emprego das geotecnologias, como as técnicas de Sensoriamento Remoto (SR) e de Geoprocessamento, apresentam vantagens como ferramentas para mapeamentos, e no monitoramento da dinâmica do uso e ocupação do território, com maior frequência na atualização de dados, expressiva redução dos custos e de tempo na elaboração dos mapas (VAEZA et al., 2010; EUGENIO et al., 2017). Para a espacialização das APP o uso dos Sistemas de Informação Geográfica (SIG) é importante instrumento para o planejamento ambiental, onde podem ser identificadas as áreas que apresentam conflitos entre uso da terra e a legislação, o que facilita a gestão do território, a fiscalização e o cumprimento da lei (COUTINHO et al., 2013). 
O Parque Estadual do Rio Preto (PERP) é uma UC de Proteção integral no Estado de Minas Gerais, criado em $1^{\circ}$ de junho de 1994 (MINAS GERAIS, 1994), o qual trouxe benefícios socioambientais, como melhoria na qualidade da água, atividades turísticas e aproveitamento sustentável dos recursos hídricos, assegurando a proteção de nascentes da bacia hidrográfica do rio Jequitinhonha, sub-bacia do Araçuaí e do rio Preto. A região apresenta a predominância do Cerrado, bioma de extrema importância, pois é estimado que no Brasil apenas 0,85\% deste esteja protegido integralmente (BRASIL, 2015), e atualmente sofre alta antropização dentre os grandes domínios vegetacionais do Brasil (BEUCHLE et al., 2015).

O PERP objetivou em sua criação a preservação do rio Preto, afluente da margem direita do rio Jequitinhonha. Localiza-se no Mosaico Espinhaço: Alto Jequitinhonha - Serra do Cabral, na porção central da Reserva da Biosfera da Serra do Espinhaço (RBSE), reconhecida em 2005 pela UNESCO (UNESCO, 2005). A RBSE é a sétima reserva da biosfera do país, e possui importância como grande divisor de águas entre bacias hidrográficas federais, por possuir espécies de fauna e flora endêmicas, expressiva biodiversidade, e por ser uma das maiores formações de Campos Rupestres do Brasil (ECHTERNACHT et al., 2011; FREITAS et al., 2012; MARQUES; NAKAJIMA, 2015; MEIRA JUNIOR et al., 2017).

O recorte deste trabalho é o PERP e sua ZA, e baseou-se em mapeamentos de uso e ocupação da terra, metodologias de delimitação de áreas de preservação permanente e áreas de uso restrito, conforme legislação vigente. Neste estudo, partimos do pressuposto de que os SIG podem gerar resultados em análise espacial da paisagem aplicáveis em tomadas de decisões ambientais e territoriais, e que alterações causadas nesta UC e sua ZA, que representam uma parte do sistema hidrológico da região, causarão desequilíbrios na dinâmica hídrica. Neste sentido, conhecer o estado de conservação de APP e AUR auxiliam em tomadas de decisão visando manutenção da qualidade dos mananciais presentes e promoção do fluxo gênico de fauna e flora na região.

Diante do exposto, a presente pesquisa objetivou identificar, por meio do uso do SIG, áreas de conflitos em APP e AUR segundo o Código Florestal vigente, visando entender o estado de conservação no Parque Estadual do Rio Preto e sua Zona de Amortecimento. 


\section{CARACTERIZAÇÃO DA ÁREA DE ESTUDO}

A área de estudo abrange o Parque Estadual do Rio Preto (PERP) e sua ZA, com área total de aproximadamente $41.408,83$ ha, Minas Gerais, Brasil, com centro de coordenadas em: $18^{\circ} 07^{\prime} 05^{\prime \prime}$ Sul e $43^{\circ} 20^{\prime} 43^{\prime \prime}$ Oeste (Figura 1). Localiza-se na porção central da Reserva da Biosfera Serra do Espinhaço (RBSE) (Figura 1) caracterizada por expressiva diversidade biológica e endemismo, rica diversidade sociocultural e por agregar áreas identificadas como insubstituíveis (MMA, 2019).

O parque situa-se no município de São Gonçalo do Rio Preto e sua Zona de Amortecimento abrange parte desse município além de áreas de Felício dos Santos e Couto de Magalhães de Minas. O PERP e a ZA apresentam altimetrias variadas, sendo sua porção sul caracterizada por cotas altimétricas mais elevadas (entre 1815 e $1249 \mathrm{~m}$ ) gradando para cotas menos elevadas em direção norte (1249 a 712 m) (Figura 1).

Regionalmente, o clima predominante é mesotérmico ( $\mathrm{Cwb}$ ), tropical de altitude quente, com microclimas diversos relacionados a fatores topográficos, temperatura média anual de 18 a $19{ }^{\circ} \mathrm{C}$, e precipitação anual de 850 a $1500 \mathrm{~mm}$ (ALVARES et al., 2013). Na região há afloramentos rochosos, Neossolos Litólicos, Quartzarênicos e Flúvico, Cambissolos e Latossolos (STCP, 2004a, b).

As principais fitofisionomias presentes são típicas do bioma Cerrado, com formações campestres (Campo Limpo e Campo Rupestre); formações savânicas representadas pelo Cerrado típico e Cerrado Ralo e por áreas com Cerrado Rupestre. Nas proximidades de córregos e rios (Florestas Ciliares) são encontradas áreas com Floresta Estacional Semidecidual em associação com formações savânicas. Outras áreas de floresta ocorrem em mosaico com a vegetação campestre, formando os "capões de mata", ou "llhas de Vegetação", observados na face Sul do PERP (STCP, 2004a, b). 


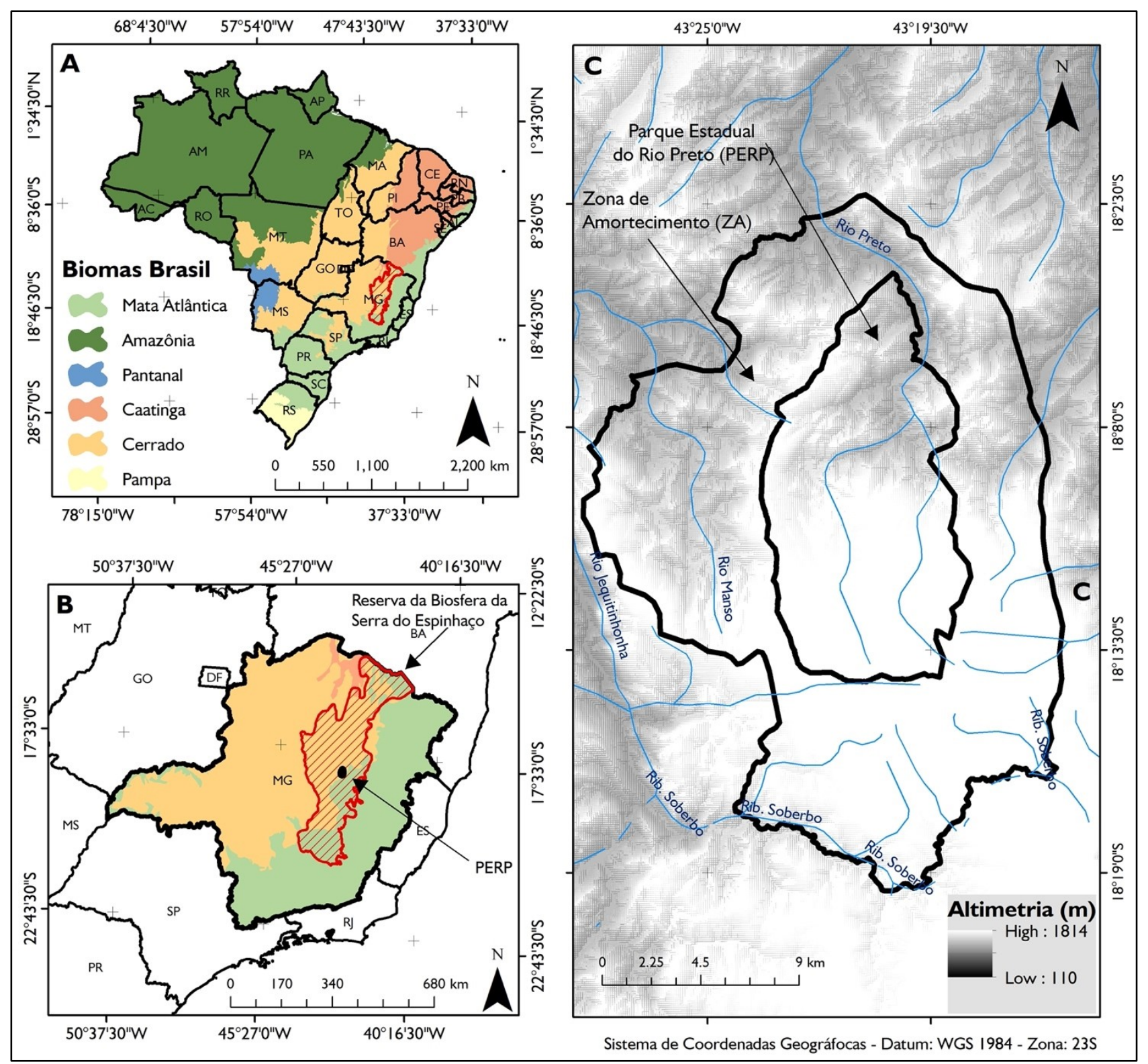

Figura 1 - Localização geográfica do Parque Estadual do Rio Preto e Zona de Amortecimento, PERP-ZA, Minas Gerais, Brasil.

Fonte: os autores

\section{MATERIAL E MÉTODOS}

\subsection{Base de dados e mapeamento do uso e ocupação da terra}

O mapa de uso e ocupação da terra foi confeccionado a partir de imagens compostas pelas cenas $23 \mathrm{kpa}$ e $23 \mathrm{kpv}$ do satélite Sentinel 2, de setembro de 2019, com resolução espacial de $10 \times 10$ m, do Serviço Geológico dos Estados Unidos (USGS, 2019). O recorte da área de estudo foi efetuado após a composição R4 (vermelho), G3 (verde), B2 (azul) em ambiente do ArcGis 10.5.1 (ESRI, 2016). Em seguida, mosaicou-se as imagens e extraiu a área de estudo, a partir de arquivo Shapefile do PERP e ZA. 
A classificação supervisionada multiespectral realizada foi a Máxima Verossimilhança (MAXVER). A imagem raster após classificação executou a filtragem para remoção de pixels isolados, e posterior conversão em arquivo Shapefile. Para os fins de acurácia da classificação, elaboramos uma matriz de erro/confusão, que é considerada a forma mais efetiva em uma classificação temática (STEHMAN, CZAPLEWSKI, 1998). Utilizou-se o coeficiente de exatidão global (STEHMAN, 1996) e o coeficiente Kappa (BISHOP; FIENBERG; HOLLAND, 1975) segundo as equações 1 e 2 respectivamente:

$$
G=\frac{\sum_{j=1}^{M} n_{i j}}{N}
$$

Em que:

$G=$ Exatidão Global;

$M=$ número de classes presentes na matriz de erro;

$n_{i j}=$ número de elementos da diagonal da matriz de confusão;

$N=$ número total de unidades amostrais contempladas pela matriz.

$$
K=\frac{N \sum X_{i i}-\sum X_{i+} X_{+i}}{N^{2}-\sum X_{i+} X_{+i}}
$$

Em que:

$K$ = Índice Kappa de concordância;

$N=$ número de observações (verdades de campo);

$X_{i i}=$ observações na linha $i$ e coluna $i$ (diagonal principal);

$X_{i^{+}}=$total marginal da linha $i$;

$X_{+i}=$ total marginal da coluna $i$.

\subsection{Base de dados e delimitação de APP e AUR}

Para a confecção dos mapas de delimitação de APP e AUR utilizou-se cenas de imagens do Modelo Digital de Elevação (MDE), provenientes do satélite ALOS (Advanced Land Observing Satellite) e sensor PALSAR (Phased Array L-band Synthetic Aperture Radar), com resolução espacial de $12,5 \times 12,5 \mathrm{~m}$, adquiridas gratuitamente no geoportal Alaska Satellite Facility/NASA (ASF, 2019).

A partir do MDE, realizamos o mapeamento das APP dos tipos: (i) nascentes e cursos d'água; (ii) bordas de tabuleiros ou chapadas; (iii) áreas com declividade superior a 
45; (iv) áreas com altitude superior a $1800 \mathrm{~m}$; e (v) AUR, áreas com declividade entre 25 e $45^{\circ}$ com base nos parâmetros, definições e limites estabelecidos pela Lei $n^{\circ} 12.651$ (BRASIL, 2012). A hierarquização fluvial foi necessária para melhor definição e ordenamento das APP de nascente e cursos d'água e seguiu a metodologia de Strahler (1952).

Geramos as informações de direção de fluxo, por meio do Arc Tool Box (Spatial Analyst Tools > Hydrology > Flow Direction), e o fluxo acumulado (flow accumulation), ou delimitação dos locais de drenagem dos cursos d'água (Spatial Analyst Tools > Hydrology > Flow Accumulation). Com base na direção de fluxo, delimitamos a hierarquia fluvial da drenagem (Spatial Analyst Tools > Hydrology > Stream Order). Com base na hidrografia fluvial geramos pontos a partir de vértices (Spatial Analyst Tools > Hydrology > Stream to Feature) para delimitação dos pontos representativos das nascentes.

Para o plano de informações de APP nascentes, executamos o comando Buffer com delimitação de raio de 50 m no seu entorno (BRASIL, 2012). As APP cursos d'água, nos rios de $4^{a}$ e $5^{a}$ ordem (com espelhos d'agua visíveis na imagem de alta resolução), mensuramos largura em 60 pontos aleatórios ao longo da hidrografia presente na área de estudo, por meio da ferramenta Mensuration, para posterior cálculo da média das larguras desses cursos d'água. As larguras médias calculadas foram de $8,5 \mathrm{~m}$ para os rios com largura de até $10 \mathrm{~m}$ e de $17,5 \mathrm{~m}$ para os de 10 a $50 \mathrm{~m}$. Com uso da ferramenta Buffer, delimitamos as zonas tampões de $30 \mathrm{~m}$ (cursos d'água com largura de até $10 \mathrm{~m}$ ) e de 50 m (cursos d'água com largura entre 10 e 50 m), conforme BRASIL (2012).

A identificação de APP de borda de tabuleiros ou chapadas foi realizada a partir da análise do MDE por meio da inserção de vetor (linha) sobre essas feições, seguido do comando Buffer unilateral de 100 m para a delimitação. As APP com declividade superior a $45^{\circ}$ foram obtidas com uso do comando Slope (Spatial Analyst Tools > Surface > Slope), gerando um raster de declividade a partir do MDE. Pelo comando Classify do Layer Symbology gerou-se classes de áreas com inclinação inferiores e superiores a $45^{\circ}$. Para reclassificação do novo raster utilizou-se o comando Reclassify, e converteu-se para Shapefile (Conversion Tools > From Raster $>$ Raster to Polygon). Em seguida, eliminamos as feições com declividade inferior a $45^{\circ}$, e calculamos as áreas dos polígonos representativos das APP com declividade superior a $45^{\circ}$ segundo metodologia de França et al. (2020). Para APP com altitude superior a $1800 \mathrm{~m}$ utilizamos o comando Classify do layer Symbology, tendo o MDE como raster de entrada, gerando classes de áreas com altitude inferiores e superiores a $1800 \mathrm{~m}$. Pelo comando reclassify obteve-se a 
reclassificação do novo raster e converteu-se para shapefile. As feições com altitude inferiores a $1800 \mathrm{~m}$ foram eliminadas, e calculou-se as áreas dos polígonos representativos das APP com altitude superior a $1800 \mathrm{~m}$.

O procedimento para cálculo das AUR, sítios com declividades entre 25 e $45^{\circ}$ seguiu procedimentos de França et al. (2018a; 2020). Realizado a partir do raster de declividade, executamos a segregação dos declives para verificar a existência ou não de AUR. Após identificação, executamos nova segregação para classificá-las, a partir do comando Classified, dividindo-as em duas (2) classes, por meio do ajuste do $1^{\circ}$ Break Value para 25 e o $2^{\circ}$ Break Value para 45 , classificando áreas abaixo de $25^{\circ}$; e áreas acima de $25^{\circ}$ e até $45^{\circ}$. Realizou-se, então, a reclassificação para o novo raster, pelo comando Reclassify e a conversão para shapefile, a partir do comando Raster to Polygon e calculou-se as áreas dos polígonos representativos das AUR.

Para a confecção do mapa de APP totais e AUR agrupamos os dados obtidos em um arquivo Shapefile, sem sobreposições, com a seguinte ordem: APP nascentes, APP cursos d'água, APP bordas de tabuleiros ou chapadas, APP com declividade superior a $45^{\circ}$, APP com altitude superior a $1800 \mathrm{~m}$ e AUR.

\subsection{Análises dos Dados}

A partir dos mapas de uso e ocupação da terra e das classes de APP e AUR, realizamos a operação de sobreposição de mapas utilizando a ferramenta Clip com objetivo de identificar as áreas conflitantes com o Código Florestal. Foram consideradas de uso adequado do solo todas as áreas com afloramento rochoso, floresta (exceto, floresta plantada), campo e água. As áreas ocupadas por floresta de eucalipto, solo exposto e agropecuária foram consideradas de uso inadequado do solo, ou seja, em desacordo a legislação vigente.

Para validação do mapeamento do uso e cobertura da terra, realizamos diagnósticos de campo nos meses de novembro de 2019 e janeiro de 2020, totalizando 5 dias. Na Figura 2 está apresentado o fluxograma das etapas realizadas para a obtenção dos resultados, subdividido no escopo metodológico geral e no detalhamento de etapas realizadas para análise de conflitos em APP e AUR no Parque Estadual do Rio Preto e Zona de Amortecimento. 


\section{Escopo Metodológico Geral}

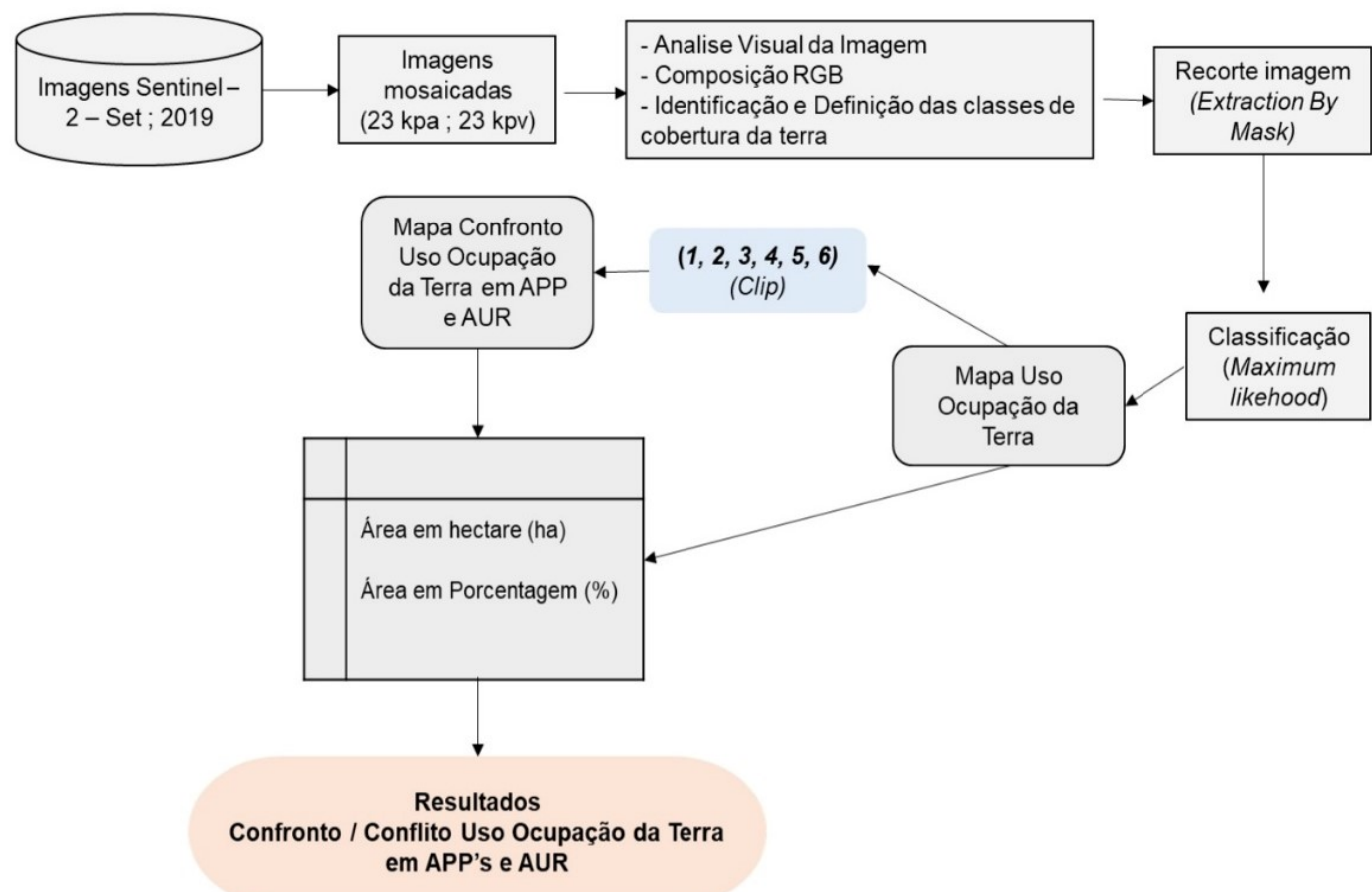

\section{Detalhamento etapas 1, 2, 3, 4, 5 e 6 (Clip)}

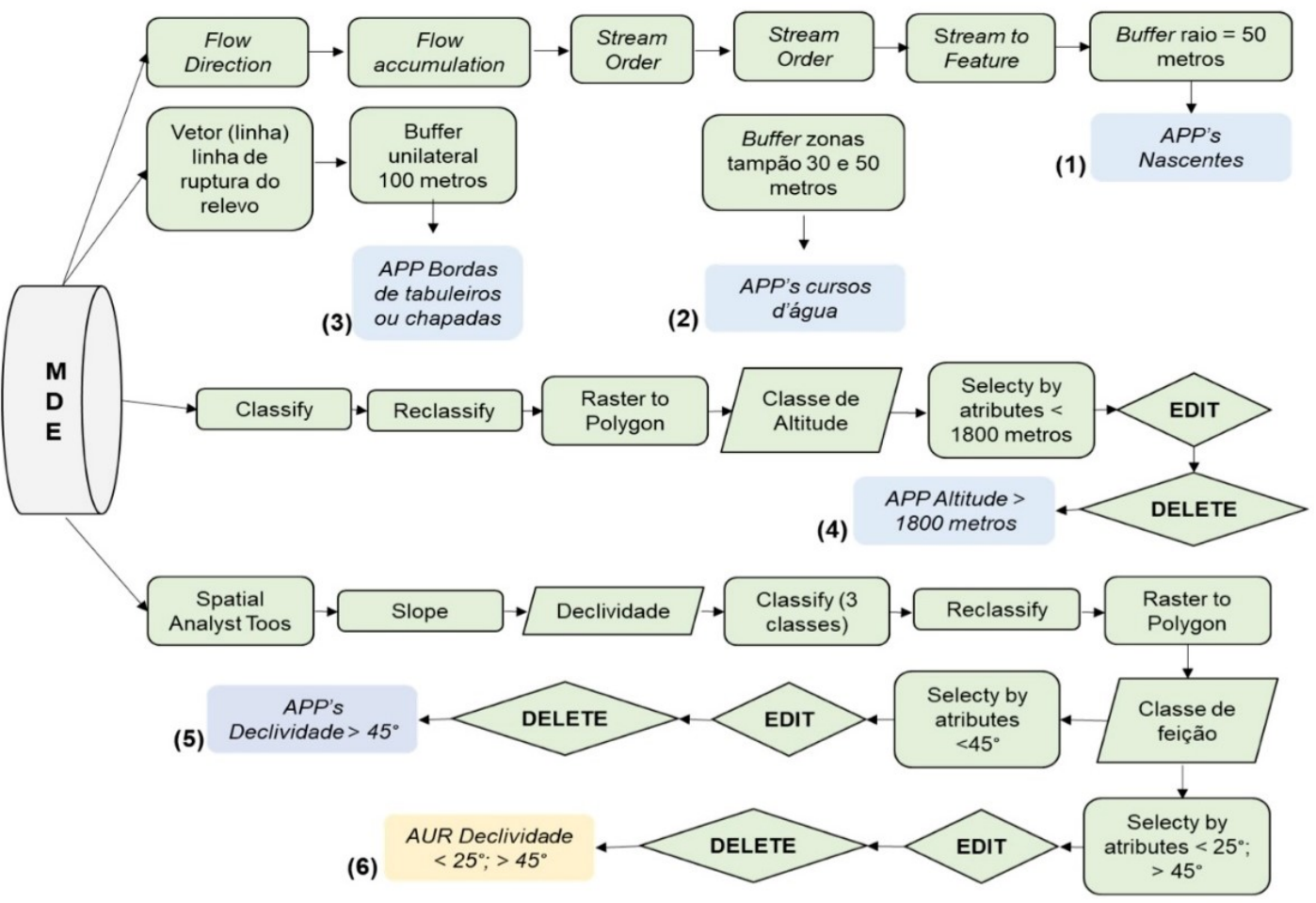

Figura 2 - Etapas realizadas para análise de conflitos em APP e AUR no Parque Estadual do Rio Preto e Zona de Amortecimento, estado de Minas Gerais, Brasil.

Fonte: Os autores. 


\section{RESULTADOS E DISCUSSÃO}

\subsection{Classes de Uso da Terra}

O mapa de uso e ocupação da terra no PERP e ZA a partir da classificação supervisionada apresentou seis classes de uso da terra: (i) Agropecuária, (ii) Formação Florestal, (iii) Formação Campestre, (iv) Água, (v) Afloramento Rochoso e (vi) Solo Exposto (Figura 3) quantificadas na Tabela 1.

Classes de uso e ocupação da terra em setembro (2019) no Parque Estadual do Rio Preto e Zona de Amortecimento, Minas Gerais, Brasil

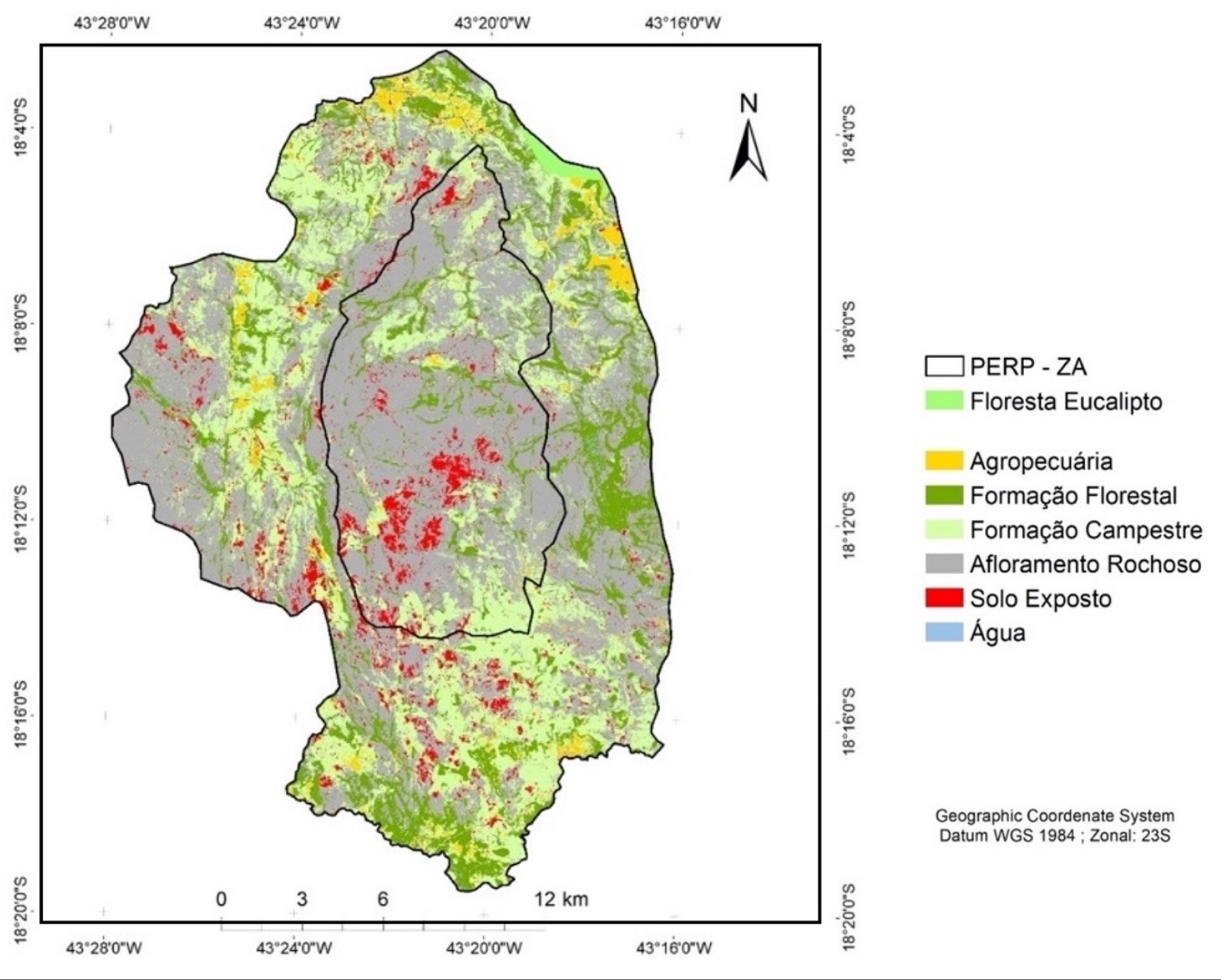

Figura 3 - Classes de uso e ocupação da terra no Parque Estadual do Rio Preto e Zona de Amortecimento, Minas Gerais, Brasil, setembro/2019.

Fonte: Os autores. 
Tabela 1 - Quantificação das classes de uso e ocupação da terra no Parque Estadual do Rio Preto e Zona de Amortecimento, no Estado de Minas Gerais.

\begin{tabular}{ccc}
\hline \multirow{2}{*}{ Classes de uso e ocupação da terra } & \multicolumn{2}{c}{ Área } \\
\cline { 2 - 3 } & (ha) & (\%) \\
\hline Afloramento Rochoso & $20.578,81$ & 49,70 \\
Formação Florestal & $5.944,37$ & 14,36 \\
Formação Campestre & $11.737,02$ & 28,34 \\
Solo Exposto & $1.912,62$ & 4,62 \\
Agropecuária & $1.115,99$ & 2,70 \\
Água & 120,02 & 0,29 \\
\hline Total $(\Sigma)$ & $41.408,83$ & 100,00 \\
\hline
\end{tabular}

Fonte: Os autores.

O resultado da classificação realizada neste trabalho corrobora com os obtidos pelo Projeto de Mapeamento Anual da Cobertura e Uso do Solo do Brasil (MAPBIOMAS, 2018), onde observamos correspondência com mesmas classes obtidas neste estudo.

A expressiva ocorrência das classes Afloramento Rochoso, Formação Campestre e Formação Florestal), totalizaram $92,40 \%$ da área de estudo. Classes de antropização observadas em menor proporção foram Solo Exposto e Agropecuária, que corresponderam a áreas de 1.912,62 ha $(4,62 \%)$ e 1.115,99 ha $(2,70 \%)$, respectivamente. A ocorrência da classe Água correspondeu a 0,29\% (120,02 ha) da área total de estudo, formada por nascentes, córregos, riachos, sendo que os que se encontram dentro da área do PERP são tributários para o Rio Preto.

A classe predominante na área foi Afloramento Rochoso, com 20.578,81 ha, 49,70\% da área total. Isto corrobora com a formação geológica predominante na região que apresenta uma grande extensão de afloramentos rochosos vinculados às rochas quartzíticas do Supergrupo Espinhaço e quartzitos sericíticos do Grupo Macaúbas (SCTP, 2004b; Morais et al. 2019). Formação Campestre apresentou área de 11.737,02 ha $(28,34 \%)$, caracterizada pela predominância de espécies herbáceas, com raros arbustos e ausência completa de árvores em áreas de solos rasos, como exemplo, Neossolos Litólicos, Quartzarênicos e Flúvicos (SCTP, 2004b). A classe Formação Florestal correspondeu a $14,36 \%$, totalizando uma área de 5.944,37 ha. Destas, cerca de 194,08 ha $(3,26 \%)$ compreendem florestas plantadas de Eucalyptus sp. no extremo Nordeste da Zona de Amortecimento do Parque. O restante vincula-se às Florestas Estacionais Semideciduais, condicionadas aos cursos d'água, distribuídas em manchas e de forma fragmentada.

Apesar de pouco significativa a presença de plantios de Eucalyptus sp. em relação a área total, é importante destacar que a expansão deste tipo de atividade pode acarretar riscos a vegetação natural, bem como potencializar os conflitos de uso da terra. Dados de 
uso e conflito da terra entre 1984 e 2013 em áreas protegidas na porção Sul do Mosaico do Espinhaço indicam expansão dessas florestas plantadas em cerca de 30.000 ha, o que pode ocasionar o aumento dos conflitos de uso de terras e a perda de conectividade na paisagem (RIBAS et al. 2016).

Diante disso, é observada a necessidade da promoção de ações na ZA do PERP buscando outras formas para obtenção de renda com o uso de espécies florestais, como por exemplo a implantação de sistemas agroflorestais (SAF's), empregando espécies nativas que apresentam potencial econômico sem gerar problemas, como a redução da conectividade entre fragmentos, que resultariam na perda do potencial gênico e ainda, de possíveis corredores ecológicos utilizados pela fauna local. Pois, os SAF's objetivam aliar melhorias na produção agrícola com qualidade ambiental, como aumento da produtividade agrícola, maior eficiência no uso de insumos e na ciclagem de nutrientes, melhoraria na fertilidade do solo, controle de erosão, conservação da biodiversidade e diversificação da renda de famílias e comunidades (LEMAIRE et al., 2014; COULIBALY et al., 2017). Além disso, destaca-se a relação direta de SAF's com ações públicas voltadas para o desenvolvimento rural, redução da pobreza rural e conservação ambiental (GONÇALVES; VIVAN, 2012), sendo estes sistemas praticados especialmente por pequenos agricultores (LORENZ; LAL, 2014).

Apesar da baixa ocorrência de Solo Exposto e Agropecuária, salientamos a potencialidade de degradação ambiental em decorrência de processos erosivos resultantes do manejo inadequado de pastagens, pastejo intensivo e/ou uso de práticas agrícolas de maneira incorreta em áreas de lavoura, podendo ainda resultar na compactação do solo, e perda de nutrientes, ocasionando o abandono da área e consequentemente o aumento de áreas com solo exposto. A grande preocupação referente a processos erosivos é justificada pela variação dos índices de Erosividade no PERP apresentados por Soares et al. (2020),

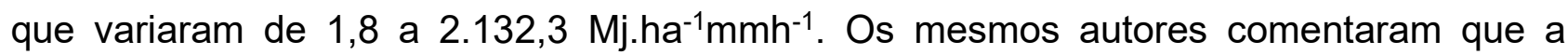
declividade do terreno, por sua vez, é uma variável importante para determinar o potencial erosivo de uma área, uma vez que quanto maior a inclinação de um terreno, maior será a velocidade de escoamento da água. Com base, nesta informação nota-se a importância da aplicação de práticas conservacionistas de solo e água por parte dos agricultores no entorno do parque visando a redução do referido problema.

Para validação dos dados apresentados anteriormente construímos a matriz de confusão (Tabela 2), cuja identificação de 54 dos 62 pontos corresponderam com as informações obtidas pela classificação supervisionada e os pontos de validação obtidos 
pela verdade de campo. O coeficiente Kappa foi de 0,80, valor considerado muito boa segundo Landis; Koch (1977). O coeficiente de exatidão global apresentou valor de 87,1\%, ou seja, superior ao aceitável estabelecido por Congalton; Green (2008) que é de $85 \%$.

A busca por mais de um caminho de validação dos dados foi realizada visto que o cálculo do coeficiente Kappa para aplicações típicas de sensoriamento remoto tem sido questionada, uma vez que pode não refletir a concordância de uma classificação, apenas descontada a casualidade (FOODY, 2020).

Tabela 2 - Matriz de confusão para a classificação supervisionada da imagem Sentinel - 2 para área de estudo.

\begin{tabular}{cccccccc}
\hline \multirow{2}{*}{ Classes } & \multicolumn{9}{c}{ Verdade de campo } & \multicolumn{2}{c}{ Total } \\
\cline { 2 - 7 } & AR & FF & FC & SE & AP & AG & $\mathbf{3 1}$ \\
AR & 31 & 0 & 0 & 0 & 0 & 0 & $\mathbf{8}$ \\
FF & 1 & 4 & 1 & 0 & 1 & 1 & $\mathbf{1 5}$ \\
FC & 2 & 0 & 11 & 1 & 0 & 1 & $\mathbf{4}$ \\
SE & 0 & 0 & 0 & 4 & 0 & 0 & $\mathbf{2}$ \\
AP & 0 & 0 & 0 & 0 & 2 & 0 & $\mathbf{2}$ \\
AG & 0 & 0 & 0 & 0 & 0 & 2 & $\mathbf{6 2}$ \\
\hline Total & 34 & 4 & 12 & 5 & 3 & 4 &
\end{tabular}

Kappa $=0,80$

Exatidão Global $=\mathbf{8 7 , 1 \%}$

Legenda: AR - Afloramento Rochoso; FF - Formação Florestal; FC - Formação Campestre; SE - Solo Exposto; AP - Agropecuária; AG - Água

Fonte: Os autores.

\section{2. Áreas de Preservação Permanente e Áreas de Uso Restrito}

De 41.408,83 há da área total do PERP e ZA, as APP do tipo nascente, cursos d'água com faixas marginais de 30 e 50 m, bordas de tabuleiros ou chapadas, áreas com declividade superior a $45^{\circ}$, áreas com altitude superior a $1800 \mathrm{~m}$ e AUR totais ocupam $7.319,31$ ha, equivalente a 17,68\% da área de estudo (Figura 4, Tabela 3). As categorias que apresentaram menor e maior ocupação foram APP altitude (áreas com altitude superior a 1800 m) e APP de cursos d'água correspondendo a 0,0045\% (1,85 ha) e 9,59\% (3.970,32 ha) da área de estudo, respectivamente. 


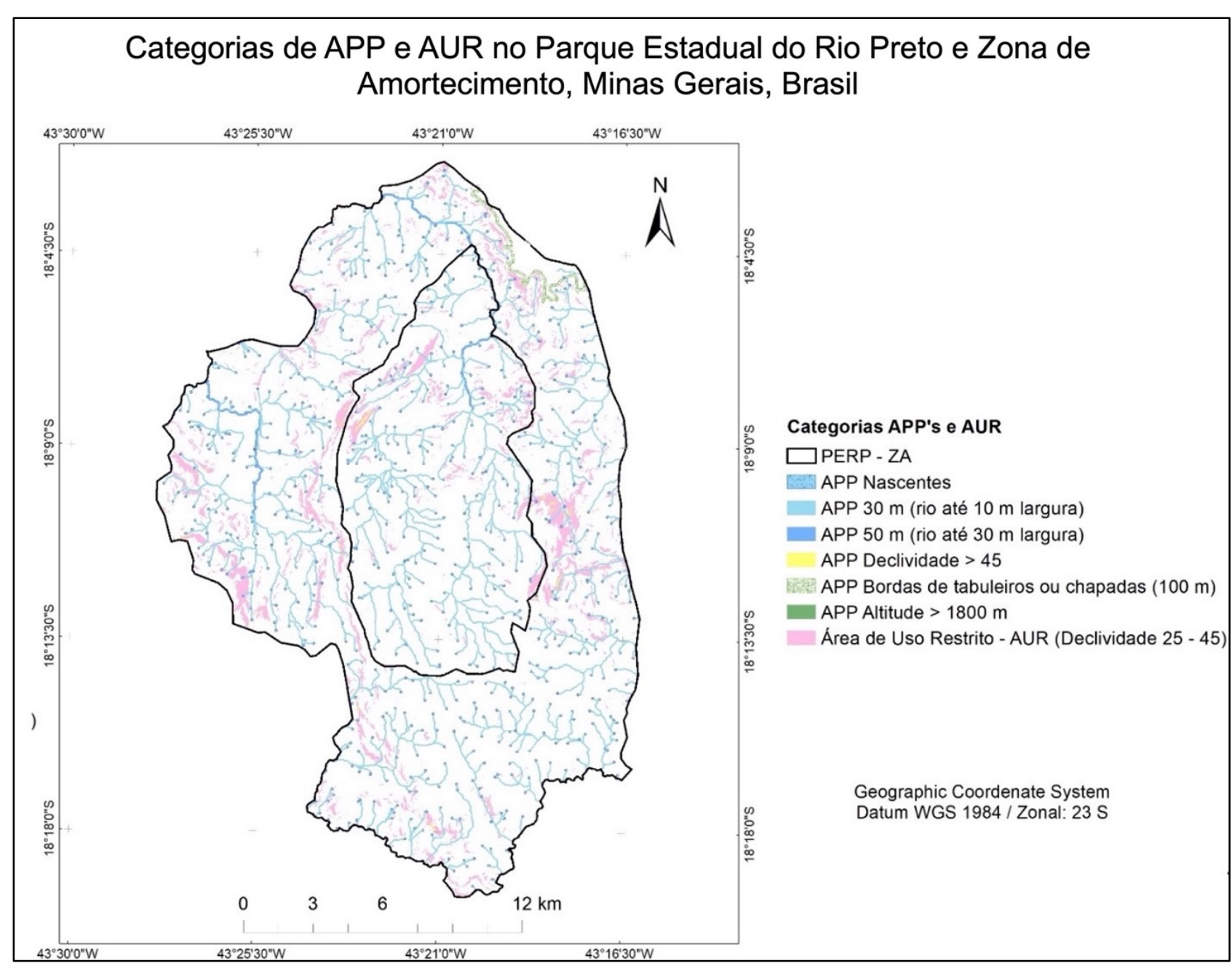

Figura 4 - Categorias de APP e AUR mapeadas no Parque Estadual do Rio Preto e Zona de Amortecimento, no Estado de Minas Gerais.

Fonte: Os autores.

Tabela 3 - Quantificação de APP e AUR no Parque Estadual do Rio Preto e Zona de Amortecimento, no Estado de Minas Gerais

\begin{tabular}{|c|c|c|c|c|}
\hline Categorias & Descrição & $\begin{array}{c}\text { Área } \\
\text { (ha) }\end{array}$ & $\begin{array}{c}\% \text { relativa à } \\
\text { área de } \\
\text { estudo }\end{array}$ & $\begin{array}{l}\text { \% relativa à } \\
\text { área total } \\
\text { das } \\
\text { categorias }\end{array}$ \\
\hline APP nascentes & Raio de $50 \mathrm{~m}$ & 615,89 & 1,49 & 8,41 \\
\hline APP cursos d'água & Largura de 30 e $50 \mathrm{~m}$ & $3.970,32$ & 9,59 & 54,24 \\
\hline APP borda de tabuleiros & Buffer de 100 m & 127,64 & 0,31 & 1,74 \\
\hline APP declividade $>45^{\circ}$ & Acima de $45^{\circ}$ & 42,62 & 0,10 & 0,58 \\
\hline APP Altitude & Acima de 1800 m & 1,85 & 0,0045 & 0,03 \\
\hline AUR & Declividade $25-45^{\circ}$ & $2.560,99$ & 6,18 & 35,00 \\
\hline Total das categorias & & $7.319,31$ & 17,68 & 100,00 \\
\hline Total da área de estudo & \multicolumn{4}{|c|}{$41.408,83$} \\
\hline
\end{tabular}

Fonte: Os autores. 
Apesar da menor ocorrência da APP de áreas com altitude superior a $1800 \mathrm{~m}$ e de sua menor representatividade dentro das categorias de áreas de preservação que foi de 0,03\%, estas devem ser preservadas pela sua importância, devido à alta biodiversidade e endemismo dos campos rupestres influenciada, dentre outros, pela variação de altitude que ocorrem nestes ambientes (FERNANDES, 2016).

Com relação às APP de cursos d'água que apresentaram maior ocupação na área total e maior representativa dentro das categorias $(54,54 \%)$, as mesmas devem ser conservadas, visto que estas exercem expressiva influência na qualidade da água doce, e aumentam a proteção de todo ecossistema de atividades antrópicas que ocorrem nas bacias hidrográficas (VALLE JUNIOR et al., 2015; ANGELSTAM; LAZDINIS, 2017; LI et al., 2018). As florestas presentes em APP de cursos d'água garantem ainda a manutenção da biodiversidade do solo, fornecem habitat para espécies aquáticas, promovem controle de inundação e estabilidade dos canais de drenagem, além de contribuírem com a recarga de aquíferos e na filtragem de sedimentos (POIANE et al., 2000; DWIRE; LOWRENCE, 2006; ANDERSON et al., 2014; NELSON et al., 2018).

A categoria APP nascentes correspondeu a aproximadamente 615,89 ha $(1,49 \%)$ do total da área analisada. Foram contabilizados no presente estudo 834 pontos de nascentes, sendo estes de suma importância para os recursos hídricos conforme mencionado por Donadio; Galbiatti; Paula (2005), no qual salientaram que uma vez sem proteção adequada no entorno das nascentes nota-se um processo de degradação do rio, havendo a necessidade de restauração da vegetação em mata ciliar como auxílio na proteção de recursos hídricos.

As APP de áreas com declividade superior a $45^{\circ}$ e de bordas de tabuleiros ou chapadas (buffer de $100 \mathrm{~m}$ ) ocupam cerca de 42,62 ha $(0,10 \%)$ e 127,64 ha $(0,31 \%)$ da área de estudo, e correspondem a 0,58 e $1,74 \%$ das áreas de preservação, respectivamente. Em relação à APP de encosta, França et al. (2018b) apontaram a alta vulnerabilidade a processos erosivos e desmoronamentos destas áreas, em especial quando desprovidas de cobertura vegetal natural para região adjacente no território da Reserva da Biosfera da Serra do Espinhaço. Tal fato denota a importância de manutenção de cobertura nestas áreas e até mesmo de implantação de ações que visem a sua preservação.

As AUR ocupam $2.560,99$ ha $(6,18 \%)$ da área total de estudo, a segunda em extensão areal dentre as categorias, equivalente a 35\%. Porém, esta difere das APP pois segundo o Código Florestal (BRASIL, 2012), estas áreas serão permitidos o manejo 
florestal sustentável e o exercício de atividades agrossilvipastoris, bem como a manutenção da infraestrutura física associada ao desenvolvimento das atividades, observadas boas práticas agronômicas, sendo vedada a conversão de novas áreas, excetuadas as hipóteses de utilidade pública e interesse social.

\subsection{Conflito de Uso da Terra}

Para identificação do conflito de uso da terra considerou-se como áreas de uso indevido as classes vinculadas às atividades antrópicas, como Agropecuária e Solo Exposto. As demais classes foram definidas de uso devido considerando a legislação vigente. A Figura 5 ilustra o uso da terra, APP e AUR por meio do cruzamento dos mapas, como produto do conflito para a área de estudo.

As classes vinculadas a sistemas naturais, Afloramento Rochoso, Formação Campestre e Formação Florestal apresentaram maior ocorrência dentro das APP, ocupando áreas de $2.129,48(44,75 \%)$ e 1.264,54 ha (26,58\%), respectivamente, o que em termos porcentuais representou $71,33 \%$ de todas as classes (Tabela 4). Solo Exposto e Agropecuária ocuparam 3,78\% (179,83 ha) e 2,41\% (114,87 ha) respectivamente, totalizando $6,19 \%$ e uma área total de 294,70 ha.

Nas áreas de APP nascentes cerca de 21,31 ha apresentam a condição de solo exposto e 17,24 ha são utilizados para a agricultura ou pecuária. Já, em áreas de cursos d'água 158,34 ha apresentam solo exposto e 91,94 ha são utilizados pela agropecuária. Estes conflitos no uso da terra promovem redução da matéria orgânica do solo e na capacidade do solo de formar agregados estáveis (VALERA et al., 2016). Assim, desenvolve-se impactos ambientais como perda de solo, diminuição na qualidade da água e da biodiversidade (VALLE JUNIOR et al., 2014; VALLE JUNIOR et al., 2015; PACHECO et al., 2016). 


\section{Uso e cobertura da terra em APP e AUR no Parque Estadual do Rio Preto e Zona de Amortecimento, Minas Gerais, Brasil}

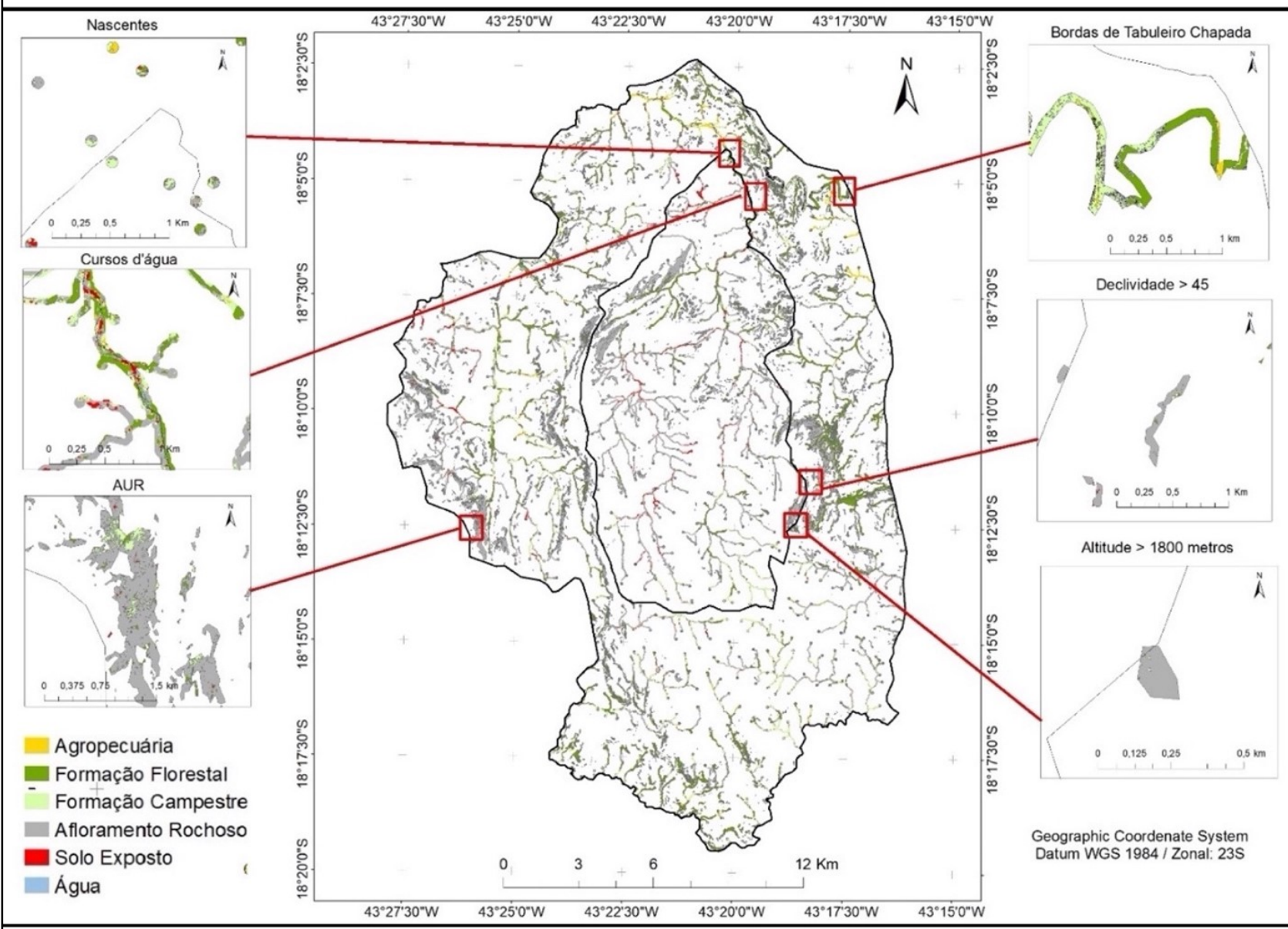

Figura 5 - Uso e cobertura da terra em APP e AUR no Parque Estadual do Rio Preto e Zona de Amortecimento, Minas Gerais, Brasil.

Fonte: Os autores.

Tabela 4. Quantificação da ocorrência de confronto de uso da terra nas categorias de APP e AUR no Parque Estadual do Rio Preto e Zona de Amortecimento, no Estado de Minas Gerais.

\begin{tabular}{|c|c|c|c|c|c|c|c|c|c|}
\hline \multirow{2}{*}{$\begin{array}{l}\text { Classes uso } \\
\text { da terra }\end{array}$} & \multicolumn{5}{|c|}{$\begin{array}{c}\text { Categoria de APP* } \\
\text { Área (ha) }\end{array}$} & \multicolumn{2}{|c|}{ APP Total } & \multicolumn{2}{|c|}{ AUR } \\
\hline & 1 & 2 & 3 & 4 & 5 & ha & $\%$ & ha & $\%$ \\
\hline Solo exposto & 21,31 & 158,34 & 0,08 & 0,10 & 0,00 & 179,83 & 3,78 & 13,80 & 0,54 \\
\hline Agropecuária & 17,24 & 91,94 & 4,29 & 1,40 & 0,00 & 114,87 & 2,41 & 21,51 & 0,84 \\
\hline Afl. Rochoso & 282,92 & $1.784,36$ & 30,23 & 30,15 & 1,82 & $2.129,48$ & 44,75 & $1.645,56$ & 64,25 \\
\hline $\begin{array}{l}\text { Formação } \\
\text { Florestal }\end{array}$ & 150,38 & $1.075,74$ & 32,44 & 5,98 & 0,00 & $1.264,54$ & 26,58 & 571,14 & 22,30 \\
\hline $\begin{array}{l}\text { Formação } \\
\text { Campestre }\end{array}$ & 142,38 & 837,65 & 60,52 & 0,91 & 0,03 & $1.041,49$ & 21,89 & 257,28 & 10,05 \\
\hline Água & 1,65 & 22,29 & 0,09 & 4,08 & 0,00 & 28,11 & 0,59 & 51,70 & 2,02 \\
\hline Total $(\Sigma)$ & 615,89 & $3.970,32$ & 127,64 & 42,62 & 1,85 & $4.758,32$ & 100 & $2.560,99$ & 100 \\
\hline
\end{tabular}

* APP1 - nascentes; APP2 - cursos d'água; APP3 - bordas de tabuleiros ou chapadas; APP4 - áreas com declividade superior a $45^{\circ}$; APP5 - áreas com altitude superior a $1800 \mathrm{~m}$.

Fonte: Os autores. 
Comparando esses resultados aos de classes de uso da terra, nota-se que as áreas utilizadas para a agropecuária se concentram na ZA, comprovando o conflito de uso da terra em 2,41\% das APP totais, o que representa a ocupação indevida de 114,87 ha. E dentre as categorias de APP observa-se que as de nascentes e cursos d'água são as mais afetadas por esta atividade, representando 15 e $80 \%$ desta ocupação indevida, respectivamente.

Uma questão levantada por Morais et al. (2013) em estudo sobre a realidade de conflitos em comunidades do entorno do PERP, refere-se a falta de planejamento e práticas políticas efetivas que realmente possam englobar as populações rurais, sobretudo as residentes nas ZA de UC. O que alerta sobre a necessidade de efetivar modelos de gestão mais participativo, de forma a integrar interesses conservacionistas àqueles das comunidades locais sendo uma tentativa de erradicar ou mesmo minimizar conflitos diretos.

Também, notamos a ação antrópica em APP de tabuleiros ou chapadas e áreas com declividade superior a 45, onde 4,29 e 1,40 ha são ocupados pela agricultura ou pecuária. Como já discutido, as classes de solos das áreas dentro e no entorno do PERP apresentam um alto grau de erosividade, o que intensifica a necessidade de aplicação de práticas adequadas nestes locais visando a sua recuperação e conservação.

Com relação à ocorrência do sistema natural o predomínio de afloramento rochoso em APP de cursos d'água (1.784,36 ha), áreas com declividade superior a $45^{\circ}(30,15 \mathrm{ha}) \mathrm{e}$ áreas com altitude superior a $1800 \mathrm{~m}$ (1,82 ha), se deve ao tipo de formação geológica da região.

A segunda maior classe de uso e ocupação do solo nas categorias de APP, com exceção de áreas com altitude superior a 1800 m, foi a de Formação Florestal, seguida da área de Formação Campestre. Sendo que esta última predominou em APP de bordas de tabuleiros ou chapadas ocupando uma área de 60,52 ha.

Apesar da classe formação florestal apresentar a segunda maior em área de uso e ocupação, 150,38 ha (APP nascentes), 1.075,74 ha (APP cursos d'água) e 5,98 ha (APP áreas com declividade superior a $45^{\circ}$ ) observa-se a necessidade de monitoramento das mesmas afim de disponibilizar dados que possam subsidiar o planejamento e aplicação de ações junto à comunidade, que potencializem o retorno das funções ecossistêmicas dessas APP, conforme mencionado por Sutton et al. (2016).

Com relação às AUR, nas quais o uso é admitido mediante manejo florestal sustentável aprovado por órgão competente, observamos situações semelhantes às APP, onde o uso e ocupação destas em nível de ocorrência seguiram a ordem de afloramento 
rochoso (1.645,56 ha), formação florestal (571,14 ha) e formação campestre (257,28 ha), com antropização em aproximadamente $35,31 \mathrm{ha}$, correspondendo a $1,38 \%$ de sua área total. Segundo o Código Florestal (BRASIL, 2012), se nestas áreas a supressão da vegetação ocorreu antes de 22 de julho de 2008, estas são consideradas consolidadas, e novas supressões de vegetação nativa para uso alternativo do solo são condicionadas à autorização do órgão estadual do meio ambiente.

O uso das AUR é condicionado também ao seu registro no Cadastro Ambiental Rural (CAR), e podem ser contabilizadas nos programas de apoio e incentivo à preservação e recuperação ambiental, tal como o PRA (Programa de Regularização Ambiental). A ocorrência de áreas de conflito, em especial, nas APP de nascentes e cursos d'água indica a necessidade de um diagnóstico ambiental, e monitoramento destas áreas, com participação ativa da comunidade, a fim de definir técnicas e ações que viabilizem a recuperação e a conservação. Segundo Rodrigues; Gandolfi (2001), um programa de recuperação pode ser planejado segundo diferentes conceitos e com etapas distintas, mas sempre há uma fase de avaliação das condições atuais da área degradada. Esta é uma das principais fases dentro de um programa, pois somente a partir de um aprofundado conhecimento dos fatores de degradação e das características da área degradada propriamente dita é que se poderá identificar as dificuldades e se definir as estratégias que deverão ser empregadas para a restauração da vegetação ciliar.

Diante dos resultados, a atualização do Plano de Manejo do PERP é uma alternativa para melhor eficiência de gestão. Segundo Morais et al. (2013), esse só foi aprovado dez anos após a sua criação em 2004. Em 2019 houve a atualização do plano de manejo (ZELLER et al., 2020) seguindo a prerrogativa a viabilidade de políticas de desenvolvimento sustentável. deve ser baseada na integração dos aspectos políticos, tecnológicos, naturais e socioculturais sob qualquer decisão ou ação visando, assim, unir áreas de conservação com todas as outras áreas relacionadas ao desenvolvimento econômico (DÍAZ et al. 2011; GÓMEZ-BAGGETHUN; RUIZ-PÉREZ, 2011).

Isso também é válido para as políticas ambientais que se baseiam na restrição de uso da terra e direitos de propriedade, desconsiderando tradições e comportamentos que resultam em resistência e indignação. Pois, a percepção é de que políticas de conservação e ambientais são criadas e aplicadas com base nos princípios de repressão ou de restrição, visando restringir atividades humanas independente das possíveis contribuições que estas possam resultar para a biodiversidade ou para a qualidade de vida (FERNANDES; 
GUIOMAR, 2016; SUROVÁ et al., 2018), resultando em conflitos de aceitação e oposição ativa às medidas e decisões.

Assim, deve-se desenvolver ações junto à comunidade a fim de educar esses atores, a importância da conservação no PERP e sua ZA, incorporando as tradições das comunidades, e promovendo o desenvolvimento sustentável da região. Estas ações devem englobar atividades econômicas que resultem em renda para as famílias, mas sem a ocorrência de conflitos em áreas protegidas por lei. Uma alternativa indicada, seria a remuneração aos proprietários que conservem e protejam as APP de nascentes, de cursos d'água, AUR, e áreas limítrofes a estas, através de programas de pagamento por serviços ambientais (PSA), uma vez que esses locais são provedores desses serviços, como a conservação da biodiversidade, a conservação das águas e dos serviços hídricos, a regulação do clima, a conservação e o melhoramento do solo (BRASIL, 2012). Mas para isso, Jäppinen; Heliölä (2015) indicaram como etapa anterior estudos de valorização desses serviços, como ferramenta importante para o planejamento holístico, a tomada de decisão e a gestão no uso da terra.

Neste estudo, os resultados obtidos vão ao encontro com as premissas estabelecidas pelo Instituto Mineiro de Gestão das Águas (IGAM) no Zoneamento Ambiental Produtivo (ZAP) de Minas gerais (MINAS GERAIS, 2020), que tem como objetivo aprimorar a gestão socioambiental e econômica de bacias hidrográficas (GORGENS et al., 2021). A adoção de um zoneamento territorial visa orientar planejamento do uso conservacionista dos recursos naturais, permite simplificar e tornar ágil a gestão e o monitoramento do uso do solo adequado no âmbito da propriedade rural e, simultaneamente, do próprio conjunto dessas propriedades nas bacias hidrográficas.

\section{CONSIDERAÇÕES FINAIS}

A aplicação da metodologia utilizando-se de ferramentas disponíveis pelo SIG mostra-se eficiente na delimitação e quantificação das áreas de uso e ocupação da terra, das categorias de APP e na análise do conflito de uso no PERP e ZA. Confirmando a potencialidade do SIG como subsídio nas políticas públicas e gestão eficiente do uso da terra.

No PERP e ZA, as classes de uso da terra afloramento rochoso e formação campestre predominaram, sendo estas consideradas de uso devido. As classes de uso 
agropecuária e solo exposto (uso indevido), apresentaram em menores proporções, indicando considerável estado de conservação desta UC.

Dentre as categorias de APP observa-se maior ocorrência das APP nascentes e cursos d'água, confirmando a importância do PERP e ZA como produtor de água para a região. Também de extrema importância no ciclo hidrológico da região, as APP declividade $>45^{\circ}$ e altitude superior a $1800 \mathrm{~m}$ apresentaram menor ocorrência.

Os usos da terra em APP nascente e cursos d'água e AUR são mais expressivos nas classes de afloramento rochoso, formação florestal e formação campestre. As classes de agropecuária e solo exposto apresentaram baixa incidência no conflito de uso em todas as APP e AUR analisadas. Porém, ao analisar sua ocorrência entre as categorias de APP verifica-se maior ocorrência de uso indevido nas APP nascentes e cursos d'água.

Assim, se faz necessária a maior participação das comunidades nos processos de gestão do PERP e ZA. Esses atores poderão sinalizar suas reais necessidades e anseios socioculturais perante a UC. Tal ação auxiliará na identificação das principais causas de degradação em áreas protegidas e no desenvolvimento de políticas públicas socioambientais coerentes e eficientes na gestão do uso da terra.

\section{AGRADECIMENTOS}

O presente trabalho foi realizado com apoio da Coordenação de Aperfeiçoamento de Pessoal de Nível Superior - Brasil (CAPES) - Código de Financiamento 001. Agradecemos o apoio do PPGCF-UFVJM, Laboratório LandLab do Centro Multiusuário de Pesquisa em Ciência Florestal da UFVJM (MULTIFLOR) e FAPEMIG.

\section{REFERÊNCIAS}

ALENCAR, G.V. Novo Código Florestal Brasileiro: ilustrado e de fácil entendimento. $1^{\text {a }}$ ed. Vitória: Ed.do autor. 2015. 313p.

ALVARES, C.A.; STAPE, J.L.; SENTELHAS, P.C.; GONÇALVES, J.L.M.; SPAROVEK, G. Köppen's Climate classification map for Brazil. Meteorologische Zeitschrift, Stuttgart, v.22, n.6, p.711-728, 2013.

ANDERSON, P.D.; POAGE, N.J. The Density Management and Riparian Buffer Study: A large-scale silviculture experiment informing riparian management in the Pacific Northwest, USA. Forest Ecology and Management, Amsterdam, v.316, p.90-99, 2014. 
ALASKA SATELLITE FACILITY. NASA. Alos Palsar. 2019. Disponível em: http://asf.alaska.edu/sar-data/palsar/ . Acesso em: 02 out. 2019.

ANGELSTAM, P.; LAZDINIS, M. Tall herb sites as a guide for planning, maintenance, and engineering of riparian continuous forest cover. Ecological Engineering, Amsterdam, v.103, p.470-477, 2017.

BARLOW, J.; LENNOX, G.D.; FERREIRA, J.; BERNGUER, E.; LEES, A.C.; NALLY, R.M.; THOMSON, J.R.; FERRAZ, S.F.B.; LOUZADA, J.; OLIVEIRA, V.H.F.; PARRY, L.; SOLAR, R.R.C.; VIEIRA, I.C.G.; ARAGÁO, L.E.O.C.; BEGOTTI, R.A.; BRAGA, R.F.; CARDOSO, T.M.; OLIVEIRA JR, R.C.; SOUZA JR, C.M.; MOURA, N.G.; NUNES, S.S; SIQUEIRA, J.V.; PARDINI, R.; SILVEIRA, J.M.; VAZ-DE-MELLO, F.Z.; VEIGA, R.C.S.; VENTURIERI, A.; GARDNER, T.A. Anthropogenic disturbance in tropical forests can double biodiversity loss from deforestation. Nature, London, v.535, p144-147, 2016.

BETTS, MG; WOLF, C.; RIPPLE, WJ; PHALAN, B.; MILLERS, KA; DUARTE, A.; BUTCHART, SHM; LEVI, T. Global Forest loss disproportionately erodes biodiversity in intact landscapes. Nature, London, v.547, n.7664, p.441-444, 2017.

BEUCHLE, R.; GRECCHI, RC; SHIMABUKURO, YE; SELIGER, R.; EVA, HD; SANO, E.; ACHARD, F. Land cover changes in the Brazilian Cerrado and Caatinga biomes from 1990 to 2010 based on a systematic remote sensing sampling approach. Applied Geography, Amsterdam, v.58, p.116-127, 2015.

BISHOP; Y.; FIENBERG, S.; HOLLAND, P. Discrete multivariate analysis: theory and practice. Cambridge: MIT, 1975. 557p.

BRASIL. Lei $\mathbf{n}^{\circ}$ 9.985, de 18 de julho de 2000. Disponível em: http://www.planalto.gov.br/ ccivil 03/leis/19985.htm. Acesso em: 20 jan. 2021.

BRASIL. Lei $\mathbf{n}^{\circ}$ 12.651, de 25 de maio de 2012. Disponível em: http://www.planalto.gov.br/ ccivil 03/ato2011-2014/2012/lei/l12651.htm. Acesso em: 20 jan. 2021.

BRASIL. MINISTÉRIO DO MEIO AMBIENTE. Mapeamento do uso e cobertura do Cerrado: Projeto TerraClass Cerrado 2013. Brasília: MMA; 2015. 67p. Disponível em: $<$ http://www.dpi.inpe.br/tccerrado/Metodologia TCCerrado 2013.pdf $>$. Acesso em: 29 jun. 2020.

BRASIL. CONSELHO NACIONAL DO MEIO AMBIENTE. Resolução CONAMA $\mathbf{n}^{\circ} . \mathbf{4 2 8}$, de 17 de dezembro de 2010. Disponível em: https://www.icmbio.gov.br/cecav/images/ download/resolucao CONAMA 428 17dez2010.PDF. Acesso em: 18 jun. 2020.

CONGALTON, RG; GREEN, K. Assessing the accuracy of remote sensing data: principles and practice. 2ed. Boca Raton: CRC Press; Francis and Taylor Group, 2008. 70p.

COULIBALY, JY; CHIPUTWA, B.; NAKELSE, T.; KUNDHLANDE, G. Adoption of agroforestry and the impact on household food security among farmers in Malawi. Agricultural Systems, Amsterdam, v.155, p.52-69, 2017. 
COUTINHO, L.M.; ZANETTI, S.S.; CECÍLIA, R.A.; GARCIA, G. de O.; XAVIER, A.C. Usos da terra e Áreas de Preservação Permanente (APP) na Bacia do Rio da Prata, Castelo ES. Floresta e Ambiente, Seropédica, v.20, n.4, p.425-434, 2013.

DÍAZ, G.I.; NAHUELHUAL, L.; ECHEVERRÍA, C.; MARÍN, S. Drivers of land abandonment in Southern Chile and implications for landscape planning. Landscape and Urban Planning, Amsterdam, v.99, p.207-217, 2011.

DONADIO, N.M.M.; GALBIATTI, J.A.; PAULA, R.C. Qualidade da água de nascentes com diferentes usos do solo na bacia hidrográfica do córrego rico, São Paulo, Brasil. Engenharia Agrícola, Jaboticabal, v.25, n.1, 2015.

DWIRE, KA; LOWRANCE, RR Riparian ecosystems and buffers-multiscale struture, function, and management Introduction. Journal of the American Water Resources Association, Washington, v.42, p.1-4, 2006.

ECHTERNACHT, L; TROVÓ, M; OLIVEIRA, C.T.; PIRANI, J.R. Areas of endemism in the Espinhaço range in Minas Gerais, Brazil. Flora-Morphology, Distribution, Functional Ecology of Plants, Amsterdam, v.206, p.782-791, 2011.

ESRI. ENVIRONMENTAL SYSTEMS RESEARCH INSTITUTE. ArcGIS 10.5: GIS by ESRI. Esri. 2016.

EUGÊNIO, F.C.; SANTOS, A.R.; FIELDLER, N.C.; RIBEIRO, G.A.; SILVA, A.G.; SOARES, P.V.; GLERIANI, J.M. Mapeamento das Áreas de Preservação Permanentes do Estado do Espírito Santo, Brasil. Ciência Florestal, Santa Maria, v.27, n.3, p.897-906, 2017.

FEISTAUER, D.; LOVATO, P.E.; SIMINSKI, A.; CASTILHO, A.C.C. Uso de indicadores baseados na legislação ambiental brasileira para análise de propriedades rurais familiares da Amazônia. Ciência Florestal, Santa Maria, v.27, n.1, p.249-262, 2017.

FERNANDES, GW The Megadiverse Rupestrian Grassland. In: FERNANDES, GW (Ed.). Ecology and Conservation of Mountaintop Grasslands in Brazil. Switzerland: Springer, p.3-14, 2016.

FERNANDES, JP; GUIOMAR, N. Environmental ethics: Driving factors beneath behavior, discourse and decision-making. Journal of Agricultural and Environmental Ethics, New York, v.29, p.507-540, 2016.

FOODY, GM Explaining the unsuitability of the kappa coefficient in the assessment and comparison of the accuracy of thematic maps obtained by image classification. Remote Sensing of Environment, Amsterdam, v.239, p.111630, 2020.

FRANÇA, L.C.J.; FERRAZ, F.T.; MUCIDA, D.P.; CARVALHO, D.; LIMA, T.P. Delimitação das áreas de uso restrito de acordo com o código florestal: uma metodologia geoespacial. In: FRANCISCO, P.R.M.; SILVA, L.M.; VAZQUEZ, G.H. Ciência, Inovação e Tecnologia: Coletânea de Publicações 2018. $1^{\text {a }}$ edição, Editora Epgraf: Campina Grande, 2018a.

FRANÇA, L.C.J.; PIUZANA, D.P.; Morais, M.S.; MENEZES, E.; MORANDI, D.T. Delimitação automática e quantificação das Áreas de Preservação Permanente de encosta 
para o município de Diamantina, Minas Gerais, Brasil. Revista Espinhaço, Diamantina, v.7, n.2, p.60-71, 2018b.

FRANÇA, L.C.J.; MUCIDA, D.P.; MORAES JUNIOR, V.T.M.; ROCHA, S.J.S.S.; REIS, C.R.; LISBOA, G.S.; SILVA, J.B.L. Áreas de Uso Restrito (AUR) em função da declividade em núcleo de desertificação no semiárido brasileiro. Acta Geografica, Boa Vista, v.14, n.34, p.74-96, 2020.

FREITAS, GH; CHAVES, AV; COSTA, LM; SANTOS, FR; RODRIGUES, M. A new species of Cinclodes from the Espinhaço Range, southeastern Brazil: insights into the biogeographical history of the South American highlands. Ibis, Weinheim, v.54, p.738-755, 2012.

GÓMEZ-BAGGETHUN, E.; RUIZ-PÉREZ, M. Economic valuation and the commodification of ecosystem services. Progress in Physical Geography, Newbury Park, v.35, n.5, p.613628, 2011.

GONÇALVES, A.L.R.; VIVAN, J.L. Agroforestry and conservation projects in Brazil: carbon, biodiversity, climate, and people. 1ed. Ipê Serra: FAO, Centro Ecológico, 2012. 36p. Disponível em: https://old.naturskyddsforeningen.se/sites/default/files/dokumentmedia/agroforestry_and_conservation_digital_print_on_screen_display.pdf. Acesso em: 30 jul. 2021.

GORGENS, E. B.; NUNRD, T. K. M. R.; MUCIDA, D. P.; SANTANA, R. C.; MORAIS, M. S.; MATOSINHOS, C. C.; DUTRA, G. C. Zoneamento Ambiental Produtivo: Bacia Hidrográfica do Ribeirão Santana - MG. 1ed. Diamantina: UFVJM, 2021. 127p.

JÄPPINEN, JP; HELIÖLÄ, J. Towards a sustainable and genuinely green economy. The value and social significance of ecosystem services in Finland (TEEB for Finland). In: JÄPPINEN, J.P.; HELIÖLÄ, J. (Eds.). The Finnish Environment 1en/2015. Helsinki: The Finnish Ministry of Environment, Helsinki, 2015.

LANDIS, JR; $\mathrm{KOCH}, \mathrm{GG}$ The measurement of observer agreement for categorical data. Biometrics, New York, v.33, n.1, p.159-174, 1977.

LEMAIRE, G.; FRANZLUEBBERS, A.; CARVALHO, P.C.F.; DEDIEU, B. Integrated croplivestock systems: strategies to achieve synergy between agricultural production and environmental quality. Agriculture Ecosystems Environment, Amsterdam, v.190, p.4-8, 2014.

LI, K.; CHI, G.; WANG, L.; XIE, Y.; WANG, X.; FAN, Z. Identifying the critical riparian buffer zone with the strongest linkage between landscape characteristics and surface water quality. Ecological Indicators, Amsterdam, v.93, p.741-752, 2018.

LORENZ, K.; LAL, R. Soil organic carbon sequestration in agroforestry systems. A review. Agronomy for Sustainable Development, Switzerland, v.34, p.443-454, 2014.

MAPBIOMAS. Projeto Mapeamento Anual da Cobertura e Uso do Solo do Brasil, 2018. Disponível em: <http://mapbiomas.org/>. Acesso em: 20 out. 2019. 
MARQUES, D.; NAKAJIMA, J.N. Heliantheae s.I. (Asteraceae) from Parque Estadual do Biribiri, Diamantina, Minas Gerais State, Brazil. Hoehnea, São Paulo, v.42, p.41-58, 2015.

MEIRA JUNIOR, M.S.; PEREIRA, I.M.; MACHADO, E.L.M.; MOTA, S.L.L.; RIBEIRO, P.S.S.P.; OTONI, T.J.O. Impacto do Fogo em Campo Sujo no Parque Estadual do Biribiri, Minas Gerais, Brasil. Floresta e Ambiente, Seropédica, v.24, p.11-14, 2017.

MINAS GERAIS. Decreto $n^{\circ}$ 35611, de 01de junho de 1994. Disponível em: http://www.siam.mg.gov.br/sla/download.pdf?idNorma=1381. Acesso em: 18 jun. 2020.

MINAS GERAIS. Metodologia do Zoneamento Ambiental e Produtivo de sub-bacias hidrográficas. 3ed. Belo Horizonte: FEAM; SEAPA, 2020.

MINISTÉRIO DO MEIO AMBIENTE. Reserva da Biosfera da Serra do Espinhaço Fase 2. 2019. Disponível em: https://www.mma.gov.br/areas-protegidas/instrumentos-degestao/reserva-da-biosfera.html. Acesso em: 18 fev. 2020.

MORAIS, M.S.; GONTIJO, B.M.; MUCIDA, D.P.; DUPIN, P.C. Comunidades e Unidades de Conservação: a realidade dos conflitos em comunidades do entorno dos Parques Estaduais do Rio Preto e Biribiri, Minas Gerais (MG). OLAM - Ciência e Tecnologia, Rio Claro, v.1, n.2, p.246-268, 2013.

MORAIS, M. S.; GONTIJO B. M.; MUCIDA, D.P.; FRANÇA, L.C.J. Uso e cobertura do terreno entre 1991 e 2011 para o Parque Estadual do Rio Preto e Zona de Amortecimento, Minas Gerais. Regnellea Scientia, Poços de Caldas, v.5, n.1, p.40-62, 2019.

MORANDI, D. T.; FRANÇA, L. C. J.; MENEZES, E. S.; MACHADO, E. L. M.; SILVA, M. D.; MUCIDA, D. P. Delimitation of ecological corridors between conservation units in the Brazilian Cerrado using a GIS and AHP approach. Ecological Indicators, Amsterdam, v. 115, p. 1-10, 2020.

NELSON, JL; HUNT, LG; LEWIS, MT; HAMBY, KA; HOOKS, CR; DIVELY, GP Arthropod communities in warm and cool grass riparian buffers and their influence on natural enemies in adjacent crops. Agriculture Ecosystems Environment, Amsterdam, v.257, p.81-91, 2018.

PACHECO, FAL; SANCHES FERNANDES, LF Environmental land use conflicts in catchments: A major cause of amplified nitrate in river water. Science of the Total Environment, Amsterdam, v.548-549, p.173-188, 2016.

PINHO, FF; FERREIRA, GB; PAGLIA, AP Influence of vegetation physiognomy, elevation and fire frequency on medium and large mammals in two protected areas of the Espinhaço Range. Zoologia, Curitiba, v.34, p e11921, 2017.

POIANI, K.A.; RICHTER, B.D.; ANDERSON, MG Biodiversity conservation at multiple scales: Functional sites, landscapes, networks. Bioscience, Oxford, v.50, p.133-146, 2000.

RIBAS, RP; CAETANO, RM; GONTIJO, BM; XAVIER, JHA Afforestation in the Rupestrian Grasslands: the augmenting pressure of Eucalyptus. In: FERNANDES, GW (Ed.). Ecology and Conservation of Mountaintop Grasslands in Brazil. 1ed. Switzerland: Springer, p.395-414, 2016. 
RODRIGUES, R.R.; GANDOLFI, S. Conceitos, tendências e ações: para a recuperação de florestas ciliares. In: RODRIGUES, R.R.; LEITÃO FILHO, H.F. (Ed.). Matas ciliares: conservação e recuperação. 2ed. São Paulo: Ed. USP, FAPESP, p.235-247, 2001.

SOARES, B.F.; FERREIRA, A.B.; BUENO, G.T.; MARTINEZ, J.H.I.A. Mapeamento do potencial erosivo do Parque Estadual do Rio Preto - MG. In: PAPROCKI, H.; MARTINEZ, J.H.I.A. (Org.). Parque Estadual do Rio Preto: geografia e diversidade. 1ed. Curitiba: Appris, 2020.111p.

SOARES-FILHO, B.; RAJÃO, R.; MACEDO, M.; CARNEIRO, A.; COSTA, W.; COE, M.; RODRIGUES, H.; ALENCAR, A. Cracking Brazil's forest code. Science, Washington, v.344, n.6182, p.363-364, 2014.

STCP ENGENHARIA DE PROJETOS LTDA. Plano de Manejo do Parque Estadual do Rio Preto. Planejamento da Unidade de Conservação. Volume I e II - Encarte 1. Curitiba, 2004a. 33p.

STCP ENGENHARIA DE PROJETOS LTDA. Plano de Manejo do Parque Estadual do Rio Preto. Planejamento da Unidade de Conservação. Volume I e II - Encarte 2. Curitiba, 2004b. 156p.

STEHMAN, SV Estimating the Kappa coefficient and its variance under stratified random sampling. Photogrammetric Engineering \& Remote Sensing, New York, v.62, n.4, p.401407, 1996.

STEHMAN, SV; CZAPLEWSKI, RL Design and analysis for thematic map accuracy assessment: fundamental principles. Remote Sensing of Environment, Amsterdam, v.64, n.3, p.331-344, 1998.

STRAHLER, A.N. Hypsometric analysis of erosional topography. Bulletin of the Geological Society of America, Maclean, v.63, p.1111-1141, 1952.

SUROVÁ, D.; RAVERA, F.; GUIOMAR, N.; SASTRE, RM; PINTO-CORREIA, T. Contributions of Iberian silvo-pastoral landscapes to the well-being of contemporary society. Rangeland Ecology \& Management, Amsterdam, v.71, p.560-570, 2018.

SUTTON, P.C.; ANDERSON, S.J.; COSTANZA, R.; KUBISZEWSKI, I. The ecological economics of land degradation: Impacts on ecosystem service values. Ecological Economics, Amsterdam, v.129, p.182-192, 2016.

UNESCO. Biosphere Reserve Information: Espinhaço Range. 2005. Disponível em: http://www.unesco.org/mabdb/br/brdir/directory/biores.asp?mode=gen\&code=BRA+06. Acesso: 18 set. 2019.

USGS. UNITED STATES GEOLOGICAL SURVEY. Free Data Proves Its Worth for Observing Earth. 2019. Disponivel em: https://www.usgs.gov/news/free-data-provesitsworth-observing-earth. Acesso em: 05 out 2019. 
VAEZA, R.F.; OLIVEIRA FILHO, P.C.; MAIA, A.G.; DISPERATI, A.A. Uso e ocupação do solo em bacia hidrográfica urbana a partir de imagens orbitais de alta resolução. Floresta e Ambiente, Seropédica, v.17, n.1, p.23-29, 2010.

VALERA, CA; VALLE JUNIOR, RF; VARANDAs, S.G.P.; SANCHES FERNANDES, LF; PACHECO, FAL. The role of environmental land use conflicts in soil fertility: A study on the Uberaba River basin, Brazil. Science of the Total Environment, Amsterdam, v.562, p.463473, 2016.

VALLE JUNIOR, RF; VARANDAS, SGP; SANCHES FERNANDES, LF; PACHECO, FAL Groundwater quality in rural watersheds with environmental land use conflicts. Science of the Total Environment, Amsterdam, v.493, p.812-827, 2014.

VALLE JUNIOR, R.F.; VARANDAS, S.G.P.; PACHECO, F.A.L.; PEREIRA, V.R.; SANTOS, C.F.; CORTES, R.M.V.; FERNANDES, L.F.S. Impacts of land use conflicts on riverine ecosystems. Land Use Policy, Amsterdam, v.43, p.48-62, 2015.

ZELLER, R.H; ALMEIDA, A.A.T.; SILVA, E.M.; MOREIRA, V.A. MOREIRA. Plano de Manejo do Parque Estadual do Rio Preto. Diamantina: IEF. 2020. 43p. Disponível em: http://www.ief.mg.gov.br/component/content/196?task=view. Acesso em: 17 jun 2021. 